\title{
Cardiac dynamics evaluation with the application of methodologies based on proportional entropy and on Zipf-Mandelbrot law
}

\author{
Javier Rodríguez, ${ }^{1}$ Signed Prieto ${ }^{2}$ and Leonardo Ramírez ${ }^{3}$ \\ ${ }^{1}$ Universidad Militar Nueva Granada, Line of Insight and Special Internship: Physics and Mathematics Applied to Medicine; ${ }^{2}$ Clínica del Country, \\ Research Center; ${ }^{3}$ Universidad Militar Nueva Granada, Bogotá, Colombia
}

\begin{abstract}
Introduction: Physical-mathematical methodologies have been useful for the diagnosis of cardiac dynamics. Objective: To compare the application of two mathematical methodologies for cardiac dynamics evaluation, one of them based on entropy proportions and the other based on of Zipf-Mandelbrot law. Method: 10 Holter, 5 acute disease dynamics and 5 normalrecords were taken. A numerical attractor was constructed; probability, entropy and entropy proportions were evaluated. To apply the second methodology, heart rate values were grouped in 15-beat/min ranges, and Zipf-Mandelbrot's law was applied in order for the statistical fractal dimension to be obtained. Finally, the mathematical evaluation obtained by both methodologies was compared. Results: The methodology based on entropy proportions differentiated normality, disease and intermediate states. The second methodology differentiated normality from acute disease through the degree of complexity. Conclusion: Both methodologies establish diagnostically helpful evaluations of cardiac dynamics in an objective and reproducible way. Proportional entropy allows normality, disease and evolution between states to be quantified in a predictive manner and with higher accuracy.
\end{abstract}

KEY WORDS: Heart rate. Entropy. Mathematics methods. Cardiac dynamics.

\section{Introduction}

In the study of cardiac dynamics, different methods have been applied by means of physical and mathematical theories, including the dynamic systems theory, probability, entropy and Zipf-Mandelbrot law. The dynamic systems theory studies systems' state and evolution. ${ }^{1}$ The representation of the behavior systems tend to is made using chaotic attractors, which are analyzed by means of fractal geometry given their irregularity. ${ }^{2}$ The study of cardiac dynamics using these methods has given rise to a neo-conception of normality and disease that contradicts the conventional position of homeostasis-based physiology. ${ }^{3}$

The mathematical language that is the substrate of modern physics is based on probability, a measurement that calculates the possible occurrence of a particular event in the future. ${ }^{4}$ In turn, entropy has been reinterpreted and applied in statistical mechanics and in the kinetic theory of gases, among other fields..$^{5-7}$ In medicine, it has been employed for the development of measurements such as approximate entropy and for the study of changes in systems' complexity. ${ }^{8-10}$ Its clinical applicability is still under study. ${ }^{9}$

Another mathematical methodology is Zipf's law, ${ }^{11}$ initially applied in linguistics to assess the frequency of words occurring in a text; for this, word frequencies were arranged from higher to lower and each one was assigned a range, starting by 1 , which increased as frequency decreased, evincing a hyperbolic behavior. Subsequently, Mandelbrot developed a linearization and created the concept of statistical fractal dimension in order to measure the degree of complexity of systems. ${ }^{12-14}$
Correspondence:

Javier Rodríguez

E-mail: grupoinsight2025@yahoo.es
Date of reception: 21-12-2016

Date of acceptance: 15-01-2018

DOI://dx.doi.org/10.24875/GMM.M18000144
Gac Med Mex. 2018;154:232-238

Contents available at PubMed www.gacetamedicademexico.com 
The importance of using these methodologies in medical fields such as cardiology lies in that cardiovascular-origin conditions are described as the leading cause of death, ${ }^{15}$ and improvement of cardiac dynamics analysis is therefore permanently sought, ${ }^{16-19}$ and has been analyzed in the light of different mathematical models that still require further study in order to corroborate their clinical applicability. ${ }^{20,21}$

Goldberger et al. ${ }^{3}$ have made a different interpretation of normality-disease within the framework of the dynamic systems theory, according to which, extremely random or very regular dynamics predominate in disease, and normality is found in the middle. New indices have been proposed to predict mortality by means of risk ratio (RR) intervals fractal analyses in patients who experience acute myocardial infarction. ${ }^{17}$ The investigations show that the approach from the conventional statistical perspective does not accurately predict heart rate variability, and it is therefore necessary to look for new options and diagnostic tools.

Another methodology developed in the same line of thought has enabled dynamics to be differentiated by means of entropy proportions. ${ }^{22}$ To confirm the clinical applicability of this methodology, blinded studies have been carried out with 450 and 600 normal and pathological cardiac dynamics, ${ }^{22,23}$ sensitivity and specificity values of $100 \%$ and a kappa coefficient $=1$ were found. This proportional entropy-based methodology was also applied for the study of cardiovascular dynamics in patients of an intensive care unit: it enabled predicting evolution to acute disease, sub-diagnosed with conventional clinical parameters. ${ }^{24}$ It has also been able to measure the level of cardiac dynamics severity in patients clinically diagnosed with arrhythmia. ${ }^{25}$

Recently, the first methodology to aid cardiac dynamics diagnosis based on Zipf-Mandelbrot law was developed. Normal and acute dynamics were mathematically characterized by means of cardiac frequencies organization hyperbolic behavior in the corresponding electrocardiographic record, which showed that the degree of complexity of dynamics without alterations is higher than that of dynamics with intensification, by means of which the state of cardiac dynamics was assessed in a simple, quantifiable and reproducible form. ${ }^{26}$ The purpose of the present research is to apply this methodology simultaneously with another diagnostic aid mathematical methodology in order to show the quantifications obtained with both methodologies.

\section{Method}

\section{Definitions}

- Delay map: Type of attractor that represents the relation between a given point of a time series plotted on the x-axis, and the next point in a time series plotted on the $y$-axis. The time series is composed of time-consecutive heart rates.

- Range of heart rate ordered pairs $(X, Y)$ : Interval of heart rates that groups all ordered pairs whose coordinates are found between the $X$ and $Y$ values. $X$ and $Y$ values are multiples of 5 for all ranges.

- Probability of the range $(X, Y)$ : Probability of finding certain number of heart rate ordered pairs in the range $(X, Y)$ (equation 1): Number of ordered pairs

$$
P(X, Y)=\frac{\text { foundin } X, Y \text { range }}{\text { Trace total ordered pairs }}
$$

Attractor entropy $(S)$ (equation 2):

$$
S=-k \sum_{x-1}^{n} \sum_{Y-1}^{n} P(X, Y) \times L n P(X, Y)
$$

Variable $S$ is entropy, $P(X, Y)$ is the probability for $X, Y$ range; $k$ is Boltzmann's constant, the value of which is $1.38 \times 10^{-23}$ joules/kelvin.

Attractor $S / k$ ratio (equation 3 ):

$$
\frac{S}{K}=-\sum_{x=1}^{n} \sum_{y-1}^{n} P(X, Y) \times \operatorname{Ln} P(X, Y)
$$

This equation can be rewritten grouping probabilities related to occupation frequencies according to values of units $P(U)$, tens $P(D)$, hundreds $p(C)$ and thousands $P(M)$. If these variables are replaced, we'll have (equation $3 a)$ :

$$
\begin{aligned}
& \frac{S}{K} \sum_{u} P(U) \times \operatorname{Ln} P(U)+\sum_{D} P(D) \times \operatorname{Ln} P(D) \\
& +\sum_{C} P(C) \times \operatorname{Ln} P(C)+\sum_{M} P(M) \times \operatorname{Ln} P(M)
\end{aligned}
$$

Which, when simplified, acquires the following form (equation 4):

$$
\frac{S}{K}=U+D+C+M
$$

Where $U, D, C$ and $M$ represent the sum of the products of range probabilities with the logarithm of this probability, which is related to the occupation frequencies in units, tens, hundreds and thousands, respectively. 
Understanding the $S / \mathrm{k}$ ratio as the totality, the equation is rewritten as follows:

$$
T=\frac{S}{K}=U+D+C+M
$$

- Entropy proportions: Proportions between parts and totality defined as $\mathrm{U} / \mathrm{T}, \mathrm{D} / \mathrm{T}, \mathrm{C} / \mathrm{T}, \mathrm{M} / \mathrm{T}, \mathrm{C} / \mathrm{M}$ and $\mathrm{D} / \mathrm{C}$

- Regions: Specific zones within the numeric attractor that were established based on normality and disease prototypes from a previous study. ${ }^{16}$ Three regions were determined: region 1 , all heart rate ranges common to all normal electrocardiographic records; region 2, all ranges occupied by normal records, except for region 1 records; region 3 , heart rate ranges not occupied by normal prototypes, the remaining region within the delay map.

- Ranges of 15 beats/minute: Heart rate (HR) intervals that include rates grouped in 15 beats/minute multiples.

- Statistical fractal dimension: It is developed by means of logarithmic linearization of the distribution of the 15-beats/minute ranges frequency of occurrence (equation 5$)$ :

$$
D=\frac{\log (\sigma+\mathrm{V})}{\log \left(\frac{F}{P}\right)}
$$

Where $D$ is the statistical dimension, $V$ is $1 / n-1$, where $n$ is the number of rates obtained on each record, $\mathrm{P}$ is the frequency of occurrence for each range and $F$ is the secondary factor associated with the point of intersection of the linearization-obtained line with the vertical axis.

\section{Population}

Ten electrocardiographic and Holter records were obtained from patients older than 21 years, 5 with normal dynamics and 5 corresponding to dynamics with acute pathology; the dynamics were taken from Insight Group databases. The records' diagnosis was carried out by an expert cardiologist according to conventional clinical parameters.

\section{Entropy-based diagnostic methodology}

For each record, heart rate maximum and minimum values were taken for each hour, as well as the number of heartbeats. With these values, a time series of the entire record was simulated and, subsequently, a numerical attractor was generated (Fig. 1), which quantifies the frequency of occurrence for each range constructed with the time series heart rate consecutive values. The probability of occupation with regard to each region was assessed; each range of heart rates was regarded as an event. Entropy was assessed for each attractor (equation 2), and the $S / k$ ratio was found (equation 3); next, the addends were grouped (equation $3 \mathrm{a}$ ) and the proportions of entropy were calculated (see definitions) for the different regions. The dynamics assessment was carried out: if there were 2 or more values not belonging to the established normality ranges, ${ }^{27}$ it was considered to be abnormal dynamics, otherwise it was considered to be normal.

To measure the different dynamics severity level, the values of proportions beyond normality intervals extreme limits were subtracted; these subtractions were grouped by units, tens, hundreds and thousands. Most acute pathological states showed higher values in the sums of the subtraction of thousands. Subsequently, the hundreds, tens and unit values were assessed.

\section{Diagnostic methodology based on Zipf-Mandelbrot law}

With the same records, the Zipf-Mandelbrot law was applied. For this, minimum and maximum heart rates were grouped into 15 beats/minute ranges and occurrence frequencies of each range were ordered from higher to lower. Each heart rate range was associated with a hierarchical range the values of which ranged from 1 to total number of ranges present in each dynamic. These values were plotted in a graph, where a hyperbolic behavior was identified; then linearization was carried out with the purpose to find the statistical fractal dimension (equation 5). Fractal dimensions for normality were found at between 0.70450 and 0.9483 and for acute disease between 0.6707 and 0.4228 , according to what previously was established by Rodríguez. ${ }^{26}$

\section{Ethical aspects}

This study was a minimum-risk investigation, according to 1993 resolution 8430 of the Colombia Ministry of Health, given that non-invasive physical and mathematical calculations are performed with paraclinical reports of procedures that were previously prescribed according to traditional medical protocols, 


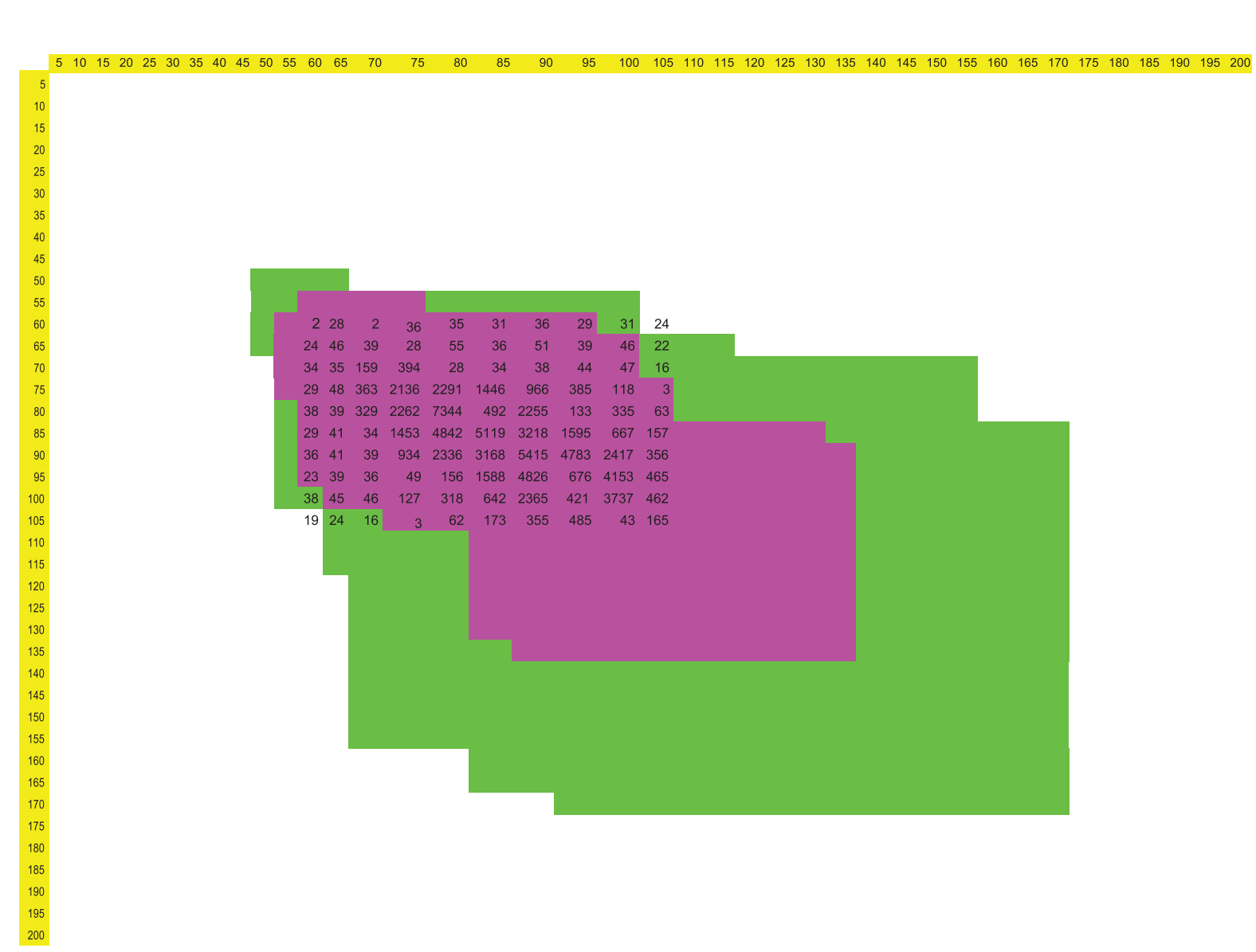

Figure 1. Numerical attractor in the space of the 3 defined regions. This attractor corresponds to table 1 dynamics 9 . The attractor colors correspond to the different regions (see definitions): region 1: purple section; region 2: green section; region 3, white section.

with participants' data and integrity being protected. In addition, it complies with the ethical principles set forth by the Declaration of Helsinki of the World Medical Association.

\section{Results}

\section{Application of the proportional entropy methodology}

Entropy values for normal records ranged from $6,49 \mathrm{E}-23$ to $7,08 \mathrm{E}-23$; for records with acute pathology, values ranged from $4,64 \mathrm{E}-23$ to $5,06 \mathrm{E}-23$. In the 5 normal records, the values of the $S / k$ ratios of the corresponding attractors ranged from -5.1271 to -4.7033 ; for the 5 patients with acute pathology, these values were found to range between -3.6648 and -3.3656 . Both the entropy and $S / k$ ratio values differentiate normality from disease, which confirms previous results. ${ }^{27}$

The values calculated for entropy ratios in normal records were found to range from 0 to 0.00838 for $\mathrm{U} / \mathrm{T}$, from 0 to 0.14056 for $\mathrm{D} / \mathrm{T}, 0$ to 0.54730 for $\mathrm{C} / \mathrm{T}, 0$ to 0.45809 for $\mathrm{M} / \mathrm{T}$, from 1.05529 to 3.22686 for $\mathrm{C} / \mathrm{M}$ and from
0.08185 to 0.18142 for $\mathrm{D} / \mathrm{C}$. In patients with acute cardiac pathology, entropy $\mathrm{U} / \mathrm{T}$ ratio values were found to range from 0 to 0.00051 , from 0 to 0.03570 for $D / T$, from 0 to 0.24406 for $C / T, 0$ to 0.81295 for $\mathrm{M} / \mathrm{T}, 0$ to 1.31495 for $\mathrm{C} / \mathrm{M}$ and from 0 to 0.24315 for $\mathrm{D} / \mathrm{C}$ (Table 1).

No value comprised within normality corresponded to the sums of entropy proportions beyond normal limits subtractions (Table 1); however, at least 2 values for patients with acute pathology were found beyond these limits.

Cardiac dynamics with higher values in the sums of subtractions of thousands correspond to the pathological states with higher clinical severity; lower values are related to acute states dynamics, but not as severe as the first ones.

\section{Application of the Zipf-Mandelbrot methodology}

The value of the records' statistical fractal dimensions were shown to range from 0.865 to 0.9892 for normality and from 0.4581 to 0.6067 for acute pathological dynamics (Table 2), which demonstrates that, 


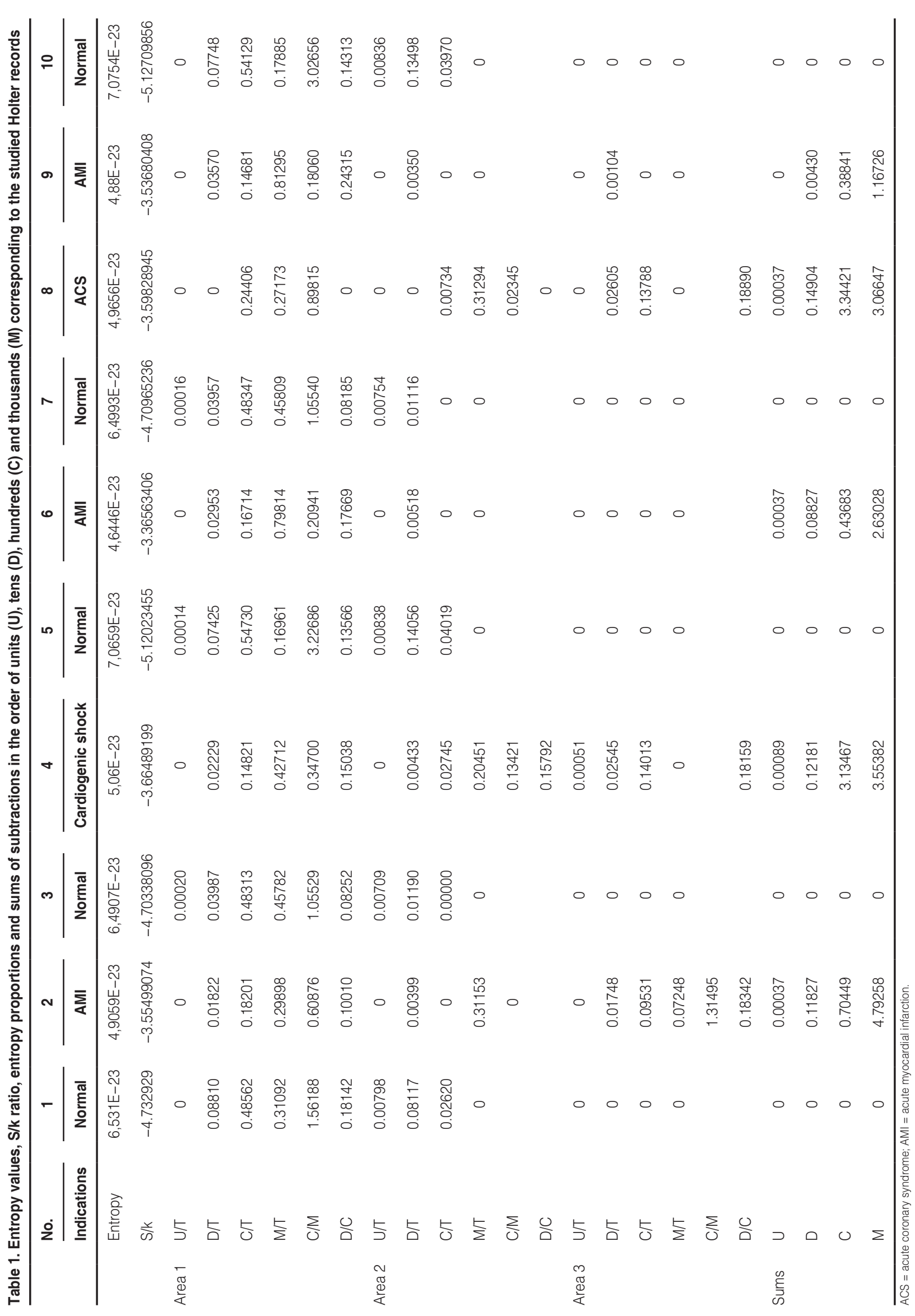


Table 2. Statistical fractal dimension (FD) and correlation factor $\left(R^{2}\right)$ values for the studied Holters

\begin{tabular}{llcc}
\hline No. & Indications & FD & $\mathbf{R}^{2}$ \\
\hline 1 & Normal & 0.9406 & 0.7526 \\
2 & Acute myocardial infarction & 0.593 & 0.782 \\
3 & Normal & 0.8791 & 0.9523 \\
4 & Cardiogenic shock & 0.4986 & 0.7577 \\
5 & Normal & 0.9892 & 0.9839 \\
6 & Acute myocardial infarction & 0.601 & 0.801 \\
7 & Normal & 0.865 & 0.7755 \\
8 & Acute coronary syndrome & 0.4851 & 0.8398 \\
9 & Acute myocardial infarction & 0.6067 & 0.9685 \\
10 & Normal & 0.9496 & 0.9774 \\
\hline
\end{tabular}

for normal dynamics, fractal dimension values of up to more than double of the fractal dimension minimum value for dynamics with acute pathology; the dynamics hyperbolic behavior was established for each record.

\section{Discussion}

This is the first work where proportional entropy methodology and Zipf-Mandelbrot-based methodology are simultaneously applied. The methodology with substrate on proportional entropy, which required assessment of both ambulatory and continuous electrocardiographic records and was based on entropy probability and proportions, showed its diagnostic predictive capability in cardiac dynamics and its capability to adequately differentiate acute from normal dynamics, showing the quantification of different levels of dynamics intensification, as well as its clinical application and usefulness for patient follow-up.

In turn, Zipf-Mandelbrot-based methodology showed its capability to differentiate acute cardiac pathology from normality based on the degree of complexity of the system, which is higher in normal cases. It should be highlighted that both methodologies are applicable to particular cases regardless of other considerations; their diagnostic capability is objective and reproducible.

Proportional entropy-based methodology has been applied in an intensive care unit ${ }^{24}$ where, when cardiac dynamics were assessed for several days, it was observed to be able to adequately predict their evolution, which proved that entropy proportions increase is indicative of exacerbation of the pathology experienced by the patient. On the other hand, remembering this methodology clinical applicability is necessary, which has been demonstrated in blinded studies with 450 and 600 cases including normal records and records with cardiac pathology. ${ }^{22,23}$ The results of the current investigation validate previous findings, demonstrating the diagnostic and predictive capability of this method.

By applying Zipf-Mandelbrot law, Rodríguez ${ }^{28}$ established differences in the degree of complexity of the T-cell repertoire specifically targeting the Poa $p 9$ allergen in an allergic patient in the presence and absence of interferon $\alpha$, which showed analogy between language phenomena ${ }^{11-14}$ and the distribution of the repertoire of T cells against the allergen. Zipf-Mandelbrot law was also applied to develop a new diagnosis with clinical application in fetal monitoring assessment. ${ }^{29}$ This diagnostic method enables clinical parameters simplification for assessment of this test, since it allows anticipating situations that are adverse to fetal well-being with more objective and reproducible parameters than conventional evaluation..$^{30,31}$

Multiple works have been carried out trying to establish useful diagnostic measures through different types of indeces, ${ }^{16-18}$ including compression entropy ${ }^{32}$ or detrended fluctuation analysis (DFA), still without broad clinical applicability. ${ }^{20,33}$ However, proportional entropy methodology application ${ }^{23,24}$ doesn't need indices, since it determines self-organization of the system in strict mathematical terms by means of entropy proportions, revealing the cardiac dynamic system general state for each particular case.

It is stressed that physical-mathematical laws and theories application to systems from the non-causal perspective has been the substrate of investigations in medicine that have given rise to new diagnostic tools and enabled the development of predictive methodologies in fields such as infectology, specifically in the prediction of CD4 lymphocytes with parameters of the hematological picture, ${ }^{34}$ in immunology, ${ }^{35}$ molecular biology in relevant topics such as malaria, ${ }^{36}$ in public health through the prediction of malaria outbreaks in Colombia, ${ }^{37}$ in studies at the arterial and cellular level, ${ }^{38,39}$ specifically in uterine cervix cells by means of Euclidian and fractal geometry and in coronary arteries by means of fractal geometry in an experimental restenosis model. Mortality predictions have also been developed in an intensive care unit based on dynamic systems and set theory ${ }^{40}$ and predictions of sepsis in neonatal cardiac dynamics. ${ }^{41}$

The described methodologies are able to characterize and predict cardiac and other type of dynamics, which shows the practical usefulness of the physical-mathematical understanding of biomedical 
phenomena and establishes applications in the diagnostic aspect that translate into opportune decision-making and solutions that are applicable in different fields of medicine.

\section{Funding}

Product deriving from INV-ING 2096 project, funded by the Universidad Militar Nueva Granada Research vice-principal office, validity 2016.

\section{Acknowledgements}

To Dr. Yanneth Méndez, Academic Vice-rector, to engineer Marcela Iregui, Research Vice-rector, to engineer Carol E. Arévalo Daza, Dean of the Faculty of Engineering, and to Dr. Elsa Adriana Cárdenas, Faculty of Engineering Research Center director. To doctors Tito Tulio Roa, Medical Education Director, Jorge Ospina, Medical Director, Alfonso Correa, Research Center director and Adriana Lisbeth Ortiz, epidemiologist, as well as to Silvia Ortiz, Research Center Chief Nurse and to Sandra Rodríguez, nurse. Also to Dr. Fernán Mendoza, cardiologist at Fundación Clínica Abood Shaio.

\section{References}

1. Devaney RL, Siegel PB, Mallinckrodt AJ, McKay S. A first course in chaotic dynamical systems: theory and experiment. EE. UU.: Addison-Wesley; 1992.

2. Peitgen $\mathrm{H}$. Length area and dimension. Measuring complexity and scalling properties. En: Chaos and fractals: new frontiers of science. EE. UU. Springer-Verlag; 1992.

3. Goldberger A, Amaral LA, Hausdorff JM, Ivanov PC, Peng CK, Stanley HE. Fractal dynamics in physiology: alterations with disease and aging. Proc Natl Acad Sci USA. 2002; 99(Suppl 1):2466-2472.

4. Laplace Pierre. Ensayo filósofico sobre las probabilidades. Barcelona: Altaya; 1995.

5. Matvéev A. Física molecular. Moscú: Mir; 1987.

6. Tolman R. Principles of statistical mechanics. EE. UU.: Dover Publications; 1979

7. Feynman RN, Leighton RB, Sands M. Leyes de la termodinámica. En Física. Volumen 1. EE. UU.: Addison-Wesley; 1964.

8. Pincus SM, Gladstone IM, Ehrenkranz RA. A regularity statistic for medical data analysis. J Clinmonit. 1991;7:335-45

9. Guillén $P$, Vallverdú $M$, Rojas $R$, Jugo $D$, Carrasco H, Caminal P. Dinámica no lineal para caracterizar la variabilidad del ritmo cardiaco en pacientes chagásticos. En: Memorias del II Congreso Latinoamericano de Ingeniería Biomédica, Cuba, 2001. Ciencia. 2003;11(4):276-283.G

10. Vikman S, Mäkikallio TH, Yli-Mäyry S, Pikkujämsä S, Koivisto AM, Reinikainen $\mathrm{P}$, et al. Altered complexity and correlation properties of R-R interval dynamics before the spontaneous onset of paroxysmal atria fibrillation. Circulation. 1999;100:2079-2084.

11. Zipf G. Human behavior and the principle of least effort: an introduction to human ecology. EE. UU.: Addison-Wesley; 1949.

12. Mandelbrot BB. Scaling and power laws without geometry. En: The fractal geometry of nature. EE. UU.G: Freeman; 1972.

13. Mandelbrot BB. Árboles jerárquicos o de clasificación, y la dimensión. En: Los objetos fractales. Barcelona: Tusquets; 2000

14. Mandelbrot B. Structure formelle des textes et comunication. World; 1954;10(1):1-27.

15. Organización Mundial de la Salud. Enfermedades cardiovasculares Ginebra, Suiza: OMS; 2011.

16. Norris PR, Anderson SM, Jenkins JM, Williams AE, Morris JA. Heart rate multiscale entropy at three hours predicts hospital mortality in 3,154 trauma patients. Shock. 2008;30:17-22.
17. Huikuri HV, Mäkikallio TH, Peng CK, Goldberger AL, Hintze U, Moller M. Fractal correlation properties of R-R interval dynamics and mortality in patients with depressed left ventricular function after an acute myocardial infarction. Circulation. 2000;101:47-53.

18. Mäkikallio TH, Hoiber S, Kober L, Torp-Pedersen C, Peng CK, Goldberger AL, et al. Fractal analysis of heart rate dynamics as a predictor of mortality in patients with depressed left ventricular function after acute myocardial infarction. TRACE Investigators. TRAndolapril Cardiac Evaluation. Am J Cardiol. 1999;83:836-839.

19. Rodríguez J, Correa C, Melo M, Domínguez D, Prieto S, Cardona DM, et al. Chaotic cardiac law: developing predictions of clinical application. J Med Sci. 2013:4(2):79-84.

20. Perkiömäki JS, Mäkikallio TH, Huikuri HV. Fractal and complexity measures of heart rate variability. Clin Exp Hypertens. 2005;27:149-158.

21. Buccelletti F, Bocci MG, Gilardi E, Fiore V, Calcinaro S, Fragnoli C, et al. Linear and nonlinear heart rate variability indexes in clinical practice. Comput Math Methods Med. 2012;2012:219080.

22. Rodríguez J, Prieto S, Domínguez D, Melo M, Mendoza F, Correa C, et al Mathematical-physical prediction of cardiac dynamics using the proportional entropy of dynamic systems. J Med Med Sci. 2013; 4(8):370-381.

23. Rodríguez J, Prieto S, Correa C, Soracipa Y, Aguirre G, Méndez L. Proportional entropy applied to the clinical diagnostic of cardiac dynamic: blind study with 600 holter. En: Memorias The $61^{\text {st }}$ Annual Conference of the Israel Heart Society in association with The Israel Society of Cardiothoracic Surgery, 2014.

24. Rodríguez J, Prieto S, Bernal P, Izasa D, Salazar G, Correa C, et al. Entropía proporcional aplicada a la evolución de la dinámica cardiaca. Predicciones de aplicación clínica. En: Rodríguez LG, coordinador. La emergencia de los enfoques de la complejidad en América Latina: implicancias políticas, epistemológicas y metodológicas para las ciencias del siglo XXI. Tomo1. Buenos Aires: Comunidad Editora Latinoamericana; 2015.

25. Rodríguez J. Mathematics physical assessment of cardiac dynamics based on theory of probability and proportions of entropy in the intensive care unit for patients with arrhythmia. Reino Unido: Medical Physics; 2015.

26. Rodríguez J, Prieto S, Correa C, Mendoza F, Weiz G, Soracipa Y, et al. Physical mathematical evaluation of the cardiac dynamic applying the Zipf-Mandelbrot law. JMP. 2015;6:1881-1888.

27. Rodríguez J. Entropía proporcional de los sistemas dinámicos cardiacos. Predicciones físicas y matemáticas de la dinámica cardiaca de aplicación clínica. Rev Col Cardiol. 2010;17(3):115-129.

28. Rodríguez J. Comportamiento fractal del repertorio $T$ específico contra el alergeno Poa p9. Rev Fac Med Univ Nac Colomb. 2005;53:72-78.

29. Rodríguez J, Prieto S, Ortíz L, Bautista A, Bernal P, Avilán N. Diagnóstico matemático de la monitoria fetal aplicando la ley de Zipf-Mandelbrot. Rev Fac Med Univ Nac Colomb. 2006;54(2): 96-107.

30. Borgatta L, Shrout PE, Divon MY. Reliability and reproducibility of nonstress test readings. Am J Obstet Gynecol. 1988;159(3):554-558.

31. Rodríguez J. Dynamical systems theory and Zipf-Mandelbrot law applied to the development of a fetal monitoring diagnostic methodology. En: Memorias del XVIII FIGO World Congress of Gynecology and Obstetrics, Kuala lumpur, Malaysia, 2006.

32. Baumert M, Baier V, Haueisen J, Wessel N, Meyerfeldt U, Schirdewan A, et al. Forecasting of life threatening arrhythmias using the compression entropy of heart rate. Methods Inf Med. 2004;43:202-206.

33. Voss A, Schulz S, Schroeder R, Baumert M, Caminal P. Methods derived from nonlinear dynamics for analysing heart rate variability. Phil Trans A Math Phys Eng Sci. 2009;367:277-296.

34. Rodríguez J, Prieto S, Correa C, Pérez C, Mora J, Bravo J, et al. Predictions of CD4 lymphocytes' count in HIV patients from complete blood count. BMC Med Phys. 2013;13:3.

35. Rodríguez J. Teoría de unión al HLA clase II: teoría de probabilidad, combinatoria y entropía aplicadas a secuencias peptídicas. Inmunologia. 2008;27(4):151-166.

36. Rodríguez J, Bernal P, Prieto S, Correa C. Teoría de péptidos de alta unión de malaria al glóbulo rojo. Predicciones teóricas de nuevos péptidos de unión y mutaciones teóricas predictivas de aminoácidos críticos. Inmunologia. 2010;29(1):7-19.

37. Rodríguez J. Método para la predicción de la dinámica temporal de la malaria en los municipios de Colombia. Rev Panam Salud Pública. 2010;27(3):211-218.

38. Rodríguez J, Prieto S, Correa C, Bernal P, Puerta G, Vitery S, et al. Theoretical generalization of normal and sick coronary arteries with fractal dimensions and the arterial intrinsic mathematical harmony. BMC Med Phys. 2010;10:1.

39. Prieto S, Rodríguez J, Correa C, Soracipa Y. Diagnosis of cervical cells based on fractal and euclidian geometrical measurements: intrinsic geometric cellular organization. BMC Med Phys. 2014;14:2.

40. Rodríguez J. Dynamical systems applied to dynamic variables of patients from the intensive care unit (ICU): physical and mathematical mortality predictions on ICU. J Med Sci. 2015;6(8):102-108.

41. Rodríguez J, Prieto S, Flórez M, Alarcón C, López R, Aguirre G, et al. Physical-mathematical diagnosis of cardiac dynamic on neonatal sepsis: predictions of clinical application. J Med Sci. 2014;5(5):102-108. 